\title{
Green chemistry concept: Applications of catalysis in pharmacuetical industry
}

\author{
Rahman $A^{*}$, Uahengo V, and Daniel LS \\ Faculty of Science, Department of Chemistry and Biochemistry, University of Namibia, Private Bag, 13301, Winhoek, Namibia
}

\begin{abstract}
Herein this article highlights the everlasting importance of catalysts in industry to synthesize value added products in chemical industry specifically focusing on pharmaceutical industry. Where large amount of drugs are produced annually and the importance of catalysts is coming into play always. There are many reactions where which do not undergo without a catalysts. The use of catalysts is quite highly profitable owing to selectivity, yield, economic and environmental friendly process. Asymmetric catalysts is the back bone and future trend in pharma industry which will irradicate the traditional multistep synthesis longer reaction times, harsh conditions required, economic and user friendly catalysts which is the required globally. Till date commercial processes have been developed using catalysts in drug industry ex: L-Dopa, Naproxin, Vitamin K, K1 Vks, Ceprozil, Cefexime, Erythromycin, Brufen, Paracetamol have been synthesized to name few there is more room for development of catalysts in chemical industry. The catalytic community have to comeup with more advanced catalysts which address growing concerns of global climate changes in order to minimize pollutants during the process development of drug synthesis.
\end{abstract}

\section{Introduction}

The first time a catalyst was used in the industry was in 1746 by J. Roebuck [1] in the manufacture of lead chamber sulfuric acid. In general catalysts is a chemical substance which increases the speed of the reaction. And many reactions without catalysts do not take place. Hence, is the utmost important to speed up the reactions in less frame of time. Since then catalysts are used in a large portion of the chemical industry. In the start only pure components were used as catalysts, but after the year 1900 multicomponent catalysts were studied and are now commonly used in the industry $[1,2]$.

In the chemical industry and industrial research, catalysis play a vital role. In order to understand the challenges facing the application of catalysts in the fine chemicals industry, one has to recognize not only the essential industrial requirements but also how the process development is carried out, and which conditions determine the suitability of a best catalyst [1,2]. Normally compounds used in Pharmaceuticals are generally complex multifunctional molecules which are built up by a sequence of chemical reactions. In this environment, catalysis is seen and is applied as a method of organic synthesis. It is used mainly to convert a functional group of a given molecule selectively into a new one in order to produce the starting material for the next synthetic step. Therefore, properties of catalysts, like chemo-, regio- or stereoselectivity are of primary interest. Additionally, catalysis is synthetically applied to form new chemical bonds or to cleave chemical bonds (e.g., reductive alkylation of amines, hydrogenolysis of carbon-halogen bonds, cleavage of protecting groups $[2,3]$.

Different catalysts are in constant development to fulfill economic, political and environmental demands. When using a catalyst, it is possible to replace a polluting chemical reaction with a more environmentally friendly alternative. Today, and in the future, this is essential for the chemical industry. In addition, it's important for a company/researcher to pay attention to market development. If a company's catalyst is not continually improved, another company can make progress in research on that particular catalyst and gain market share. In pharmaceutical and partly also in the fine chemicals industry many chemical conversions require stoichiometric amounts of reagents, and thus generate large amounts of copious waste [2,3]. This is in contrast to the production of bulk chemicals which mostly relies on catalysis. This difference can be explained by the higher complexity of pharmaceuticals and fine chemicals which makes catalysis more demanding and process development more expensive. The first known use of bromine for medical purposes was back in 1835. Previously used as a sedative in the 19th and early 20th century, today it is used in both drugs and as a catalyst for the manufacturing of pharmaceuticals.

\section{Over-the-counter and prescription drugs}

While much attention has been focused to developing catalysis for particular substrates, often insufficient devotion has been paid to the impactof preparation of these substrates on the overall process effectiveness $[3,4]$. Thus, the benefits of the catalyticstep may be nullified if the synthesis and purification of the substrate add extra steps. Forexample, the preparation of pure E- or Z-vinyl compounds is often difficult and the purificationof imines may present an issue. This issue meritsgreater attention to prevent subsequent effort onthe optimization of the catalytic step beingwasted.

Having inherited Union Carbide's expertise following that takeover, Dow pharma have further developed arange of bis--phosphite ligands, principally one known as BIPHEPHOS, (9), that gives satisfactoryrates

Correspondence to: Ateeq Rahman, Faculty of Science, Department of Chemistry and Biochemistry, University of Namibia, Private Bag, Winhoek, Namibia, E-mail: ateeqr786@yahoo.com

Key words: Pharmaceutical, Cefprozil, asymmetric synthesis Lindlar catalysts

Received: February 14, 2017; Accepted: March 25, 2017; Published: March 28, 2017 
and high yields of linear aldehydesfor a wide variety of substrates. Reactions cantypically be carried out at 3 bar pressure and $80^{\circ} \mathrm{Cwith}$ a substrate: catalyst ratio of around $1000[3,4]$.

In numerous therapeutic drugs the active component is a single enantiomer. Normally, chemical reactions give enantiomeric mixtures as the products. Subsequent purification, for example, by fractional crystallization, to isolate the active enantiomer is an extra process that adds to production costs (Figure 1).

By using chiral catalysts - or asymmetric catalysts - the single active enantiomer can be produced. William Knowles in the 1970 s found that rhodium bonded to chiral phosphine ligands could perform asymmetric catalytic hydrogenation. The method was soon developed for the commercial production of the anti-Parkinson drug, 1-dopa (Scheme 1). In 2001 Knowles shared the Noble Prize in chemistry with Ryoji Noyori and K. Barry Sharpless $[5,6]$ for their research on asymmetric catalysis. Currently, with the enormous expansion of the pharmaceutical industry, there is demand for chiral compounds and other chiral catalysts are now being developed.

\section{Hydrogenation of $\mathrm{C}=\mathrm{C}$ double bonds}

Hydrogenation is a chemical process used in a wide range of industrial applications, from food products, such as margarine, to petrochemicals and pharmaceuticals. The process classically involves the use of heavy metals, such as palladium or platinum, to catalyze the chemical reaction $[5,6]$. While these metals are very efficient catalysts, they are also non-renewable, costly, and subject to sharp price fluctuations on international markets. Undoubtedly, the most common hydrogenation reaction performed in industry is the hydrogenation of carbon-carbon double bonds. A wide variation of catalysts are available from commercial suppliers. $\alpha$-Tocopherol is the economically most important member of the group of vitamin $\mathrm{E}$ compounds, due to its biological and antioxidant properties. This fat-soluble vitamin is produced on a scale of $>30^{\prime} 000$ tonnes per year (mostly in form of its acetate derivative for applications in human and animal nutrition. One of the key building blocks for the chemical production of synthetic vitamin $\mathrm{E}$ is trimethylhydroquinone (TMHQ,) (1), which is converted into (all-rac)-a-tocopherol by condensation with (all-rac)-isophytol (2) [7-9] this transformation is considered a robust and atom-economical reaction leading to (all-rac)-a-tocopherol (3) and finally Vitamin E (4) (Scheme 2).

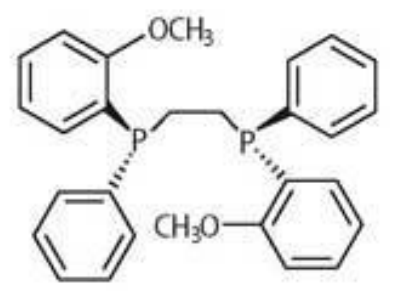

Phosphine ligand

Figure 1. Phosphine ligand [4].

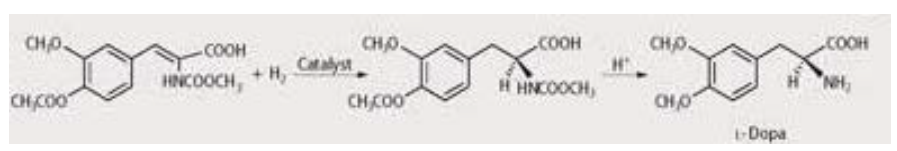

Scheme 1. Assymmetric hydrogenation of carbon-carbon double bond [5-6].
A noteworthy stereo-selective hydrogenation of a tri-substituted olefinic $\mathrm{C}=\mathrm{C}$ double bond was used in several total synthesis routes to the water-soluble vitamin (+)-biotin [10]. This product is produced on a scale of about 100 tonnes per year, and only the $(3 \mathrm{a} S, 4 S, 6 \mathrm{a} R)$ stereoisomer exhibits full biological activity. Stereocenter C-4 of the thiophane ring can be introduced by catalytic hydrogenation of the exocyclic olefin with indefinite double-bond stereochemistry on $\mathrm{Pd} / \mathrm{C}$ or other heterogeneous catalysts, yielding with the desired all-cis relative configuration at centers $\mathrm{C}-4, \mathrm{C}-3 \mathrm{a}$, and C-6a. The N-benzyl protecting groups are stable under those conditions. This approach, originally developed by Goldberg and Sternbach $[11,12]$, was later on used by other groups in various syntheses of racemic and optically active intermediates [10-12] (Scheme 3,4).

According to Sheldon's groupsing [2,3], most vitamins are typical fine chemicals with production volumes of about 100 to $10^{\prime} 000$ tons per year. Various vitamins can be placed in the class of bulk chemicals. Generally, these compounds have been produced industrially for decades in multi-step synthesis with high overall yields. The application of catalytic methods in the highly competitive field of vitamins has increased substantially in recent years because of price pressure on these products. Research and development is consequently driven by<smiles>C=CC(C)(O)CCCC(C)CCCC(C)CCCC(C)C</smiles>

(all-rac)- $\alpha$-tocopherol 3<smiles>CC(=O)OCCCC(C)CCCC(C)CCCC1(C)CCc2c(C)c(OC(C)=O)c(C)c(C)c2O1</smiles>

Scheme 2. Final steps for the production of Vitamin E [7-9].

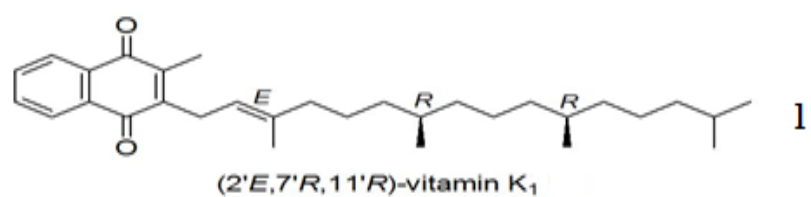<smiles>CC/C(C)=C/CC1=C(C)C(=O)c2ccccc2C(=O)C1(C)C</smiles>

vitamins $K_{2}(n=4-13)$<smiles>CC1=CC(=O)c2ccccc2C1=O</smiles>

vitamin $\mathrm{K}_{3}$ 


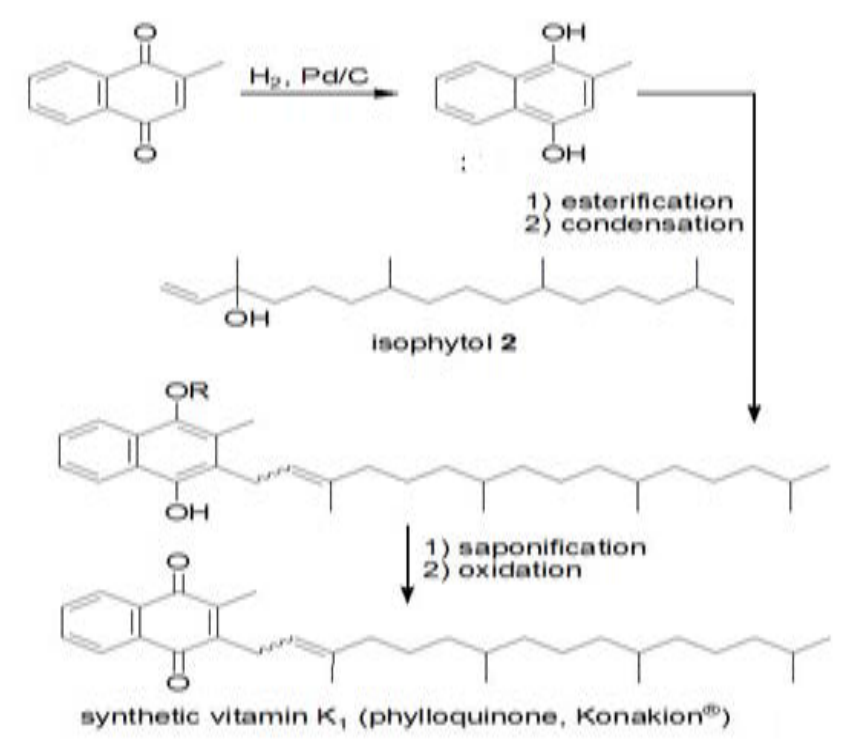

Scheme 4. Synthesis of Vitamin K1 [7-9].

unavoidability to reduce waste, use of less toxic reagents and solvents, improve energy efficiency, recycle catalysts and reagents, and combine unit operations to reduce costs and achieve more sustainable processes [3].

\section{Semi-hydrogenation of $\mathrm{C} \equiv \mathrm{C}$ triple bonds (Lindlar type)}

The semi-hydrogenation of carbon-carbon triple bonds to alkenes is one of the most valuable hydrogenations for the production of vitamins, however careful choice of catalyst and reaction conditions are required to achieve high selectivity [13]. In general, hydrogenation of acetylenes with a metal catalyst results in the formation of the fully saturated alkane product, while the second hydrogenation (alkene to alkane) is generally faster than the first (alkyne to alkene). Nonetheless, as long as some of the starting alkyne remains in the reaction mixture, selectivity can be high since the alkynes unite more strongly to the metal surface. The selectivity can be improved by the use of suitable catalyst poisons which modify the activity of the metal catalyst. One of the most widely used and most selective catalysts is the one originally developed by Lindlar [13-19]. Among this catalyst, the palladium supported on calcium carbonate is doped with a lead acetate solution during manufacture. This catalyst can then be used either directly in the hydrogenation or modified further by an organic compound such as an amine. Since the hydrogen is delivered from the metal surface to the alkyne, usually high selectivity is obtained for the $Z$-(cis)-alkene product. "Lindlar catalysts" generally have $5 \%$ palladium loading and $2-5 \%$ lead loading, depending on the application. One of the earliest uses of the catalyst developed by Lindlar [13-19] was the semihydrogenation of a vitamin A key intermediate (2) to give tetraene (2). Whilst this could be achieved with poisoned palladium on charcoal or palladium on calcium carbonate [15-19], selectivity's were significantly higher with the lead-doped catalyst and the reaction could easily be stopped after the uptake of just one equivalent of hydrogen gas.

\section{Improved methods for catalyst recovery in biopharmaceutical production}

Active Pharmaceutical Ingredient (API) processes employs catalytic organic synthesis which provides cleaner processes and hence, greener chemistries. These processes fairlyuse transition metal catalysts that have several advantages of traditional reaction chemistries [3].
They allow mostly fast reactions which require fewer steps than stoichiometric reagents. They operate at lower temperatures, pressures, decreasing capital costs and providing a higher degree of safety. Solitary example is the Ullman reaction, which uses copper to couple two aryl halides to form the biaryl molecule. Few more notable examples of coupling chemistries which use transitional metal catalysts are Heck, Suzuki and Fukuyama reactions. In the transitional metals, the platinum group metals (PGM) are commonly used for pharmaceutical syntheses. PGMs include ruthenium $(\mathrm{Ru})$, rhodium $(\mathrm{Rh})$, palladium $(\mathrm{Pd})$, osmium (Os), iridium (Ir) and platinum (Pt) [1-3,13-15] (Scheme 5,6).

Selected examples for the applications of (phase transfer catalysts) PTC for syntheses of biologically active compounds, taken mostly from recent literature. Synthesis of Sibenadet hydrochloride [16-19] is a potent drug used for treatment of chronic obstructive pulmonary disease, includes $\mathrm{O}$-alkylation process carried out on about one hundred kilogram scale in PTC system (Scheme 7).

Banwell and coworkers [20,21] reported the synthesis of natural products (or their analogs) and other compounds possessing biological activity, in which readily available gem -dihalogenocyclo- propanes were used as building blocks. Synthesis of an alkaloid (ñ)-erythramine, isolated from a variety of plant sources, which displays cardiovascular activity and molluscicidal properties (Scheme 8).

\section{Synthesis of Cefprozil}

Hdeaki Hoshi, Ichikawa et al. [22-24] reported an alternatie

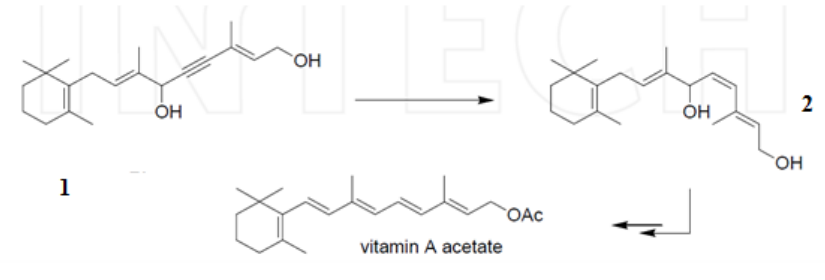

3

Scheme 5. Semi hydrogenation of Vitamin A intermediate [13-15].

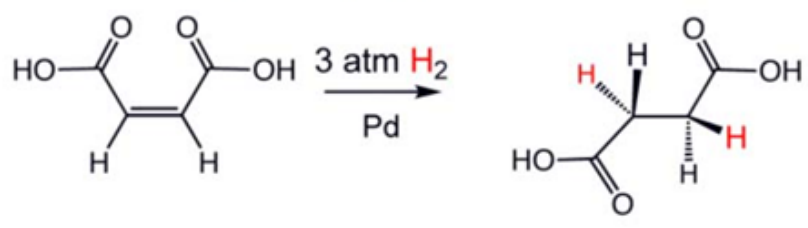

Scheme 6. Shows an example of a hydrogenation reaction catalyzed by palladium.
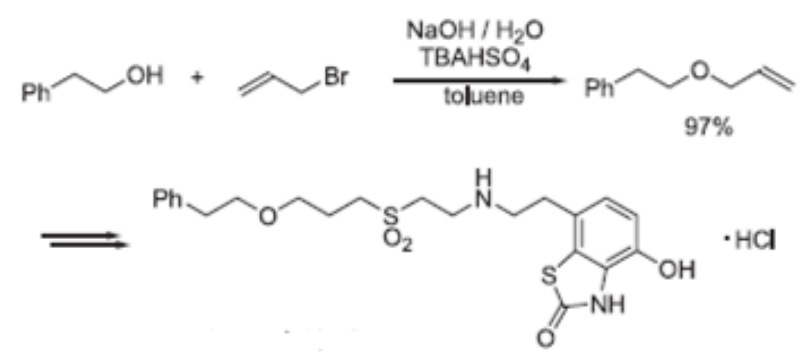

Scheme 7. Synthesis of Sibenadet hydrochloride [20-21]. 
method of synthesis of Cefprozil by introducing propenyyl group at C3 position of Cephem compound (10) by wittig reaction of the triphenylphosphoranyl intermediate derivetaldehyded from a 33-chloromethylcephem compound (5) with the acetaldethyde using 10 equivalents of lithium halides ex: lithium bromide or lithium iodide to achieve a $\mathrm{Z}$ to $\mathrm{E}$ ratio 9:1. The reaction is carried out in dichloromethane and co-solvent selected from dimerthyl formamide or isopropyl alcohol at a temperature $0-25^{\circ} \mathrm{C}$; yield $71 \%$. The cephem compound (14) is further deacylated using $\mathrm{PCl}_{5}$ in presence of organic base pyridine folloed by alcoholysis using 1,3-butandiol at $-20^{\circ} \mathrm{C}$ then
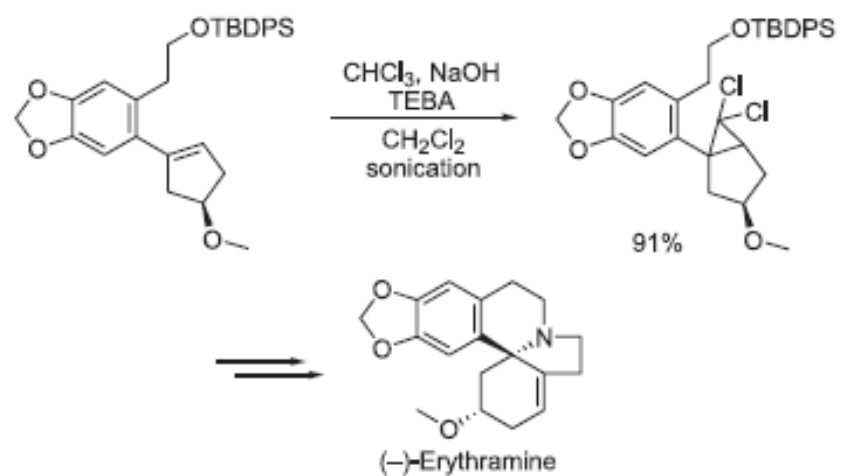

Scheme 8. Synthesis of Erythramine [20]. deprotecting the carboxy group with TFA in anisole at $0 \mathrm{oC}$ resulted into an intermediate 7-Amini-3-(propenyl-1-yl)-3-cephem-4-carboxylic acid (7-APCA-(16) which on condensation with D-p-hydroxylphenyl glycylchloride hydrochloride in presence of organic base resulted in final product as Cefprozil [22-25] (Scheme 9).

\section{Catalyst recovery}

Catalyzed reactions can be broadly classified into two categories: heterogeneous and homogeneous. In heterogeneous reactions, the phase of catalyst is different from that of reactants, i.e. solid, liquid or gas $[19,20]$. However, it can also mean that the miscibility of the catalyst is different from the reaction mixture too. With homogeneous reactions, the catalyst and other reactants are the same phase and are miscible with one another. The type of reaction will have implications for the recovery of the catalyst post-reaction, which is a cumbersome method comparing to heterogeneous catalysts where the reaction mixture is filtered.

Solvent extraction, filtration, nano filtration, chemical precipitation, and adsorption are catalyst recovery techniques typically employed in industrial and pharmaceutical processes. Nanofiltration recovery is used only with homogeneous processes and catalysts are immediately re-used in the liquid phase. Therefore, nano filtration is not principally amenable to incineration and recovery of the catalysts for future use. Solvent extraction and chemical precipitation tend<smiles>NC1C(=O)N2C(C(=O)O)=C(COC(=O)CO)CSC12</smiles>

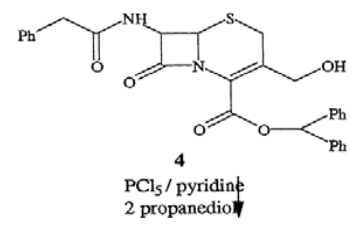<smiles>CC(=O)OCC1=C(C(=O)O)N2C(=O)C(NC(=O)Cc3ccccc3)C2SC1</smiles><smiles>C#CC(=O)OC(=O)C1=C(CCl)CSC2C(N)C(=O)N12</smiles><smiles>N=C(OC(=O)C1=C(CCl)CSC2C(NC(=O)[C@@H](NCc3ccccc3)c3ccc(O)cc3)C(=O)N12)C1CCCCC1</smiles>

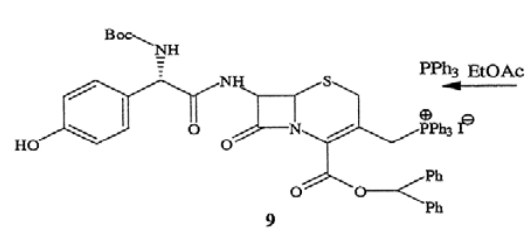<smiles>O=C(OC(=O)c1ccc(O)cc1)C1=C(CI)CSC2C(NC(=O)C(NCc3ccccc3)c3ccccc3)C(=O)N12</smiles>
8

$\mathrm{NaOH}, \mathrm{CHCl}_{3}$<smiles>O=C[C@H]1CC[C@@H]2CC[C@H]1C2</smiles><smiles>CC=CC1=C(C(=O)Oc2ccccc2)N2C(=O)C(NC(=O)[C@H](NCc3ccccc3)C(C)=CC)C2SC1</smiles><smiles>CC(C)CC1CSC2C(NC(=O)[C@@H](N)c3ccc(O)cc3)C(=O)N2C1C(=O)O</smiles> 
to be somewhat non-specific and can lead to yield losses of the API. Adsorptive recovery techniques can include materials such as activated carbon and ion exchange resins to recover either homogeneous catalysts, or homogeneous ligand and/or leachate. With a homogeneous catalyst, the carbon or resin will selectively absorb the catalyst. The catalyst is then stripped from the adsorbent for reuse or sent to a recovery specialist for incineration and recovery. For a homogeneous ligand and/or leachate, a fragment of a heterogeneous catalyst is shed and then dissolved in the phase where the chemical transformation is taking place. The catalyst is filtered from the batch and the ligand and and/or leachate that remains in solution is removed via resin or carbon treatment.

\section{The problem with carbon}

Traditionally, adsorption techniques for catalyst recovery have involved activated carbon. Carbon is well characterized, it is relatively inexpensive and it is relatively effective in removing spent catalysts from process streams [13-19]. However, carbon suffers from several drawbacks. First, it can be difficult to handle and filter from the process stream. This is usually overcome by operating the removal process with pre-packed carbon cartridges. The second, and more difficult, drawback is the non-specific adsorptive nature of carbon. Carbon will remove the catalyst, but it will also bind a percentage of the API. This leads to yield losses and increased production costs. The selective removal of the catalyst would be a more attractive adsorption option.

\section{A more selective approach: Ion exchange resins}

Ion exchange resin technology has been used for over 60 years in the bio-pharmaceutical industry, primarily for purification of APIs. Molecules as diverse as antibiotics, oligonucleotides and monoclonal antibodies have been purified using ion exchange resins. Specialized ion exchange resins are also used as scavengers for chemical synthesis, removing byproducts and un-reacted components [1-7]. These uses range in scale from laboratory bench-top operations, such as solid phase extraction (SPE) strategies with combinatorial libraries, to fullscale production. One example of a scavenger resin at production-scale in industrial processing is the use of imino-diacetic functionalized resin for metal removal. The waste effluent before discharge still contains some low levels of heavy metals, about 5 to $20 \mathrm{ppm}$. A polishing unit containing the chelating resin installed in a packed-column merry-goround configuration can bring the total concentration of metals below $0.1 \mathrm{ppm}$ even in the presence of high concentrations of sodium or calcium salts [1-7].

\section{Improved methods for catalyst recovery in biopharma- ceutical production}

Active Pharmaceutical Ingredient (API) processes employ catalytic organic syntheses which provide cleaner processes and hence, greener chemistries. These processes quite often use transition metal catalysts that have several advantages of traditional reaction chemistries [21-24].

\section{Conclusion}

Catalysis has come a long way and has served industry well in empowering many reactions to be done which, otherwise, would have been uneconomic or even impossible. Today chemists are faced with new challenges as concerns for the environment and scarcity of resources motivates them to look for greener processes. Since most of the major drugs are enantiomeric excesss the main focus has been driven on nano asymmetric catalysts where only single step is involved compared to the conventional which goes through multi step synthesis. Many processes have been developed till date using catalysts in pharmaceutical industry ex: L-Dopa, Naproxin, Vitamin K, K1 and many more Vks have been synthesized, Ceprozil, Cefexime, Paracetamol to name few there is more room for development of catalysts in chemical industry. In this communication, the author's have emphasized on the applications of catalysts in pharmaceutical industry how it is beneficial to the pharmaceutical industry which will bring in long way in the near future making way for nano catalysts/catalysts greener process, economically and ecofreindly.

\section{Acknowledgement}

Authors acknowledge University of Namibia supporting this project.

\section{References}

1. Roebuck, John 1746. Dictionary of National Biography. London: Smith, Elder \& Co. 1885-1900.

2. Sheldon RA, van Bekkum H (2001) Fine Chemicals through Heterogeneous Catalysis.

3. Weinheim, Germany: Wiley-VCH. Sheldon RA (2000) Atom efficiency and catalysis in organic synthesis. Pure Appl Chem 72: 1233-1246.

4. Angrick M, Kümmerer K, Meizner L (2006) Nachhaltige Chemie. Erfahrungen und Perspektiven, Reihe Ökologie und Wirtschaftsforschung, 66. Marburg, Germany: Metropolis.

5. Knowles WS (2002) Asymmetric hydrogenations. Angew Chem Int Ed 41: 1998-2007.

6. Noyori R (2002) Asymmetric catalysis: science and opportunities. Angew Chem Int 41: 2008-2022.

7. Baldenius KU, Hunnefeld L, Hilgemann E, Hoppe P, Stürmer R (1996) Chapter 4 Vitamin E (Tocopherols, Tocotrienols). In: Ullmann's Encyclopedia of Industrial Chemistry, A 27. Weinheim, Germany: VCH: 478-488.

8. Bonrath W, Eggersdorfer M, Netscher T (2007) Catalysis in the industrial preparation of vitamins and nutraceuticals. Catal Today 121: 45-57.

9. Netscher T (2007) Synthesis of Vitamin E. Vitamins and Hormones 76: 155-202.

10. De Clercq (1997) Biotin: A Timeless Challenge for Total Synthesis. Chem Rev 97 1755-1792.

11. Isler O, Huber W, Ronco A, Kofler M (1947) Synthese des Vitamin A, Helv. Chim Acta 30: 1911-1927.

12. Goldberg MW, Sternbach L.H (1949) Synthesis of biotin. US 2489232.

13. Goldberg M.W, Sternbach L.H 1949 Synthesis of biotin. US 2489235.

14. Lindlar H (1952) Ein neuer Katalysator für selektive Hydrierungen, Helv. Chim Acta 35: 446-450.

15. Lindlar H (1954) Hydrogenation of acetylenic bond utilizing a palladium-lead catalyst. US2681938.

16. Lindlar H, Dubuis R (1966) Palladium Catalyst for Partial Reduction of Acetylenes. Organic Syntheses 45: 89-92.

17. United States Environmental Protection Agency (2010) 'Green Chemistry'

18. Anastas PT, Eghbali N (2010) Green Chemistry: Principles and Practice. Chem Soc Rev 39: 301-312.

19. Sabatier P, Sendrens JB (1900) H.ydrogenation of ethylene in presence of differen metals. Comptes Rendus Hebdomadais des Seances. de l'Academie des science 130: 1781.

20. Sabatier P, Sendrens JB (1899) Action of hydrogen on acetylene in presence of nickel. Comptes Rendus Hebdomadais des Seances. de 1'Academie des science 128: 1173.

21. Banwell, Stanislawski, Anthony, Banwell (2007) gem-Dihalocyclopropanes as Building Blocks in Natural-Product Synthesis: Enantioselective Total Syntheses of entErythramine and 3-epi-Erythramine. Chemistry An Asian Journal 2: 1127-1136.

22. Cosgrove SD, Steele G, Austin TK, Plumb AP, Stensland B (2005) Understanding the Polymorphic Behavior of Sibenadet Hydrochloride through Detailed Studies Integrating Structural and Dynamical Assessment. Journal of Pharmacuetical Sciences 94: $2403-2415$

23. Hoshi H, Ichikawa (1985) United States Patent. US 4,520,022. 
Rahman A (2017) Green chemistry concept: Applications of catalysis in pharmacuetical industry

24. Hoshi H, Ichikawa, Jun Kumara (1987) Dose response study of caudal neostigmine for

25. U.S. Pharmacopia (2000) 24: 348. postoperative analgesia. US 4, 699, 979 .

Copyright: $\odot 2017$ Rahman A. This is an open-access article distributed under the terms of the Creative Commons Attribution License, which permits unrestricted use, distribution, and reproduction in any medium, provided the original author and source are credited. 